\title{
A study of provincial differences in China's eco-compensation framework
}

\author{
LIU Chunla ${ }^{1,2}$, LIU Weidong ${ }^{2}$, LU Dadao ${ }^{2},{ }^{*}$ CHEN Mingxing ${ }^{2}$, XU Mei ${ }^{3}$ \\ 1. Department of Resources and Environment Science, Hunan Normal University, Changsha 410008, China; \\ 2. Institute of Geographic Sciences and Natural Resources Research, Key Laboratory of Regional Sustainable \\ Development Modeling, CAS, Beijing 100101, China; \\ 3. School of Tourism, Central South University of Forestry and Technology, Changsha 410004, China
}

\begin{abstract}
In this study, we developed a theoretical framework to analyze the provincial differences in eco-compensation and selected appropriate measurement methods to investigate these differences in the operation of the eco-compensation framework. Via the use of the coefficient of variation, Atkinson index, and Gini coefficient, we investigated the overall differences in Chinese provincial eco-compensation time series data from 2004 to 2014 and studied the driving mechanism underlying these differences. The results showed that: (1) The provincial eco-compensation standard has geographical features. For example, the provinces crossed by the "HU Huanyong Line", or located to its northwestern side, have obtained extensive eco-compensation. (2) There was a trend for differences in eco-compensation to increase over time, but with some fluctuations in 2006, 2009, and 2014 as shown by the coefficient of variation, in 2005, 2007, 2011, 2013, and 2014 as shown by the Gini coefficient, and in 2007, 2008, 2011, and 2012 as shown by the Atkinson index. (3) Time series curves indicated that while the signals from the three metrics (coefficient of variation, Atkinson index, and Gini coefficient) differ in a short-term analysis, they show the same tendency in the longer term. The results indicate that it is necessary to evaluate the differences in eco-compensation at the provincial level over a long period of time. (4) Via the calculation of the virtual Gini coefficient, we found that among the factors that influence provincial differences in eco-compensation, the economic value of eco-resources played the decisive role, explaining more than $73 \%$ of the difference. The cost of environmental pollution abatement was the second most important factor, accounting for more than $19 \%$ of the difference. The input to environmental pollution abatement had the least influence, accounting for less than $8 \%$ of the difference. The results agreed with those obtained from other studies, and could be used as a reference by policy makers.
\end{abstract}

Keywords: provincial eco-compensation; difference; measure; China

Received: 2016-08-02 Accepted: 2016-09-29

Foundation: National Natural Science Foundation of China, No.41601143, No.41671125, No.41125005; The Foundation of Humanities and Social Sciences of the Ministry of Education, No.16YJC840012; The Philosophy and Social Science Foundation of Hunan Province, No.15YBA273; The Science and Technology Planning Project of Hunan Province, No.2016SK2019

Author: Liu Chunla, PhD, specialized in economic geography and regional development. E-mail: liuchunla111@163.com

"Corresponding author: Chen Mingxing, PhD and Associate Professor, E-mail: chenmx@igsnrr.ac.cn 


\section{Introduction}

Eco-compensation is an important issue for ecologists, resource scholars, geographers, and government managers in China and overseas (SDSRG, ACCA, 2007; ACCA, 2012; Xie et al., 2015; Liu et al., 2016). There have been many studies of eco-compensation schemes and their differences (Salzman et al., 2000; Boyd et al., 2007; Wünscher et al., 2008; Yang et al., 2007; Qin et al., 2007; Yuan et al., 2014; Liu et al., 2015). Outside of China, eco-compensation is referred to as payment for ecosystem services (PES) or payment for ecological benefits (PEB). International studies of differences in eco-compensation have focused on the aspects of natural environment eco-compensation, the spatio-temporal distribution of eco-compensation, and human and economic eco- compensation. Studies of differences in natural environment eco-compensation frameworks are at an early stage overseas, and have mostly focused on plant tolerance to herbivory and its eco-compensation. For example, the differences in the eco-compensation provided for plants damaged from herbivores have been considered (Strauss et al., 1999), as has the impact of herbivory on different plants used as natural resources, and a comparison of the problems inherent in eco-compensation has been attempted (Hawkes et al., 2001). The spatial and temporal distribution of eco-compensation is an important research focus. For example, modeling procedures have been used to design compensation payments for the efficient spatio-temporal allocation of species protection measures (Johst et al., 2002), and spatially uniform versus spatially heterogeneous compensation payments have been considered for biodiversity-enhancing land-use measures (Wätzold et al., 2005). Human and economic eco-compensation and the differences between each framework have been an important focus of international studies in recent years. Such studies have considered the institutional dimensions of payments for ecosystem services (Corbera et al., 2009), eco-compensation scope and equity implications (Börner et al., 2010; Wunder et al., 2008), and payments for ecosystem services as commodity fetishism and the differences in such payments (Kosoy et al., 2010).

In China, studies of the differences in eco-compensation schemes have mainly focused on differences in the eco-compensation standard, stakeholders, and the type and mechanism of compensation. Some studies of the differences in eco-compensation standards have been based on questionnaire surveys of the willingness to pay for eco-compensation (Li et al., 2011; Yang et al., 2012), method modeling (Zhang et al., 2010; Ma et al., 2012), and related comparative studies (Xiong et al., 2004; Chen, 2011). There are large differences in the various eco-compensation standards in use worldwide. For the same objective, if different measures are adopted, there are different standards in use. Studies of the differences in types of eco-compensation have mostly focused on river basin eco-compensation (Ruan et al., 2008), forest eco-compensation (Li et al., 2007), and regional eco-compensation (Li et al., 2009; Xu et al., 2015). Studies of the differences in eco-compensation mechanisms have referred to the type of eco-compensation mechanism (Jiang, 2010), and have subdivided the type of eco-compensation, as well as designing plans to implement the various schemes (Huang et al., 2010). Studies of the differences in the subjects of interest in specific eco-compensation schemes have involved detailed comparisons of these subjects ( $\mathrm{Li}$ et al., 2011), and the spatial selection of eco-compensation objectives (Dai, 2010). Moreover, many researchers have undertaken comprehensive analyses of these problems, and compared 
the differences between schemes.

Provincial differences in eco-compensation are an important aspect of eco-compensation, and are closely related to regional development and ecological construction (Zhao et al., 2010; Ding et al., 2012; Wu et al., 2003). In China, it is necessary and feasible to conduct investigations of provincial eco-compensation. Provincial eco-compensation (inter-regional eco-compensation) can not only advance the coordinated development of regional economies (Hu et al., 2007; Wang et al., 2010), but also promote eco-environmental protection during regional development (Ding et al., 2008). At the same time, to solve the development issues in various types of restricted and forbidden development zones in the main functional areas of China, we need to promote regional eco-compensation at different scales (Ding et al., 2012). Regional eco-compensation is critical at state level. There have been quantitative studies of provincial eco-compensation based on economics, ecological value equivalents, and other related factors (Song et al., 2010; Jin, 2009; Cai et al., 2005; Liu et al., 2014; Wang et al., 2011; Wu et al., 2013). In practice, it is feasible to conduct provincial eco-compensation in China. The government action pattern (An et al., 2012), market model, and non-governmental organization (NGO) model, have been used in some locations, and will be used in Chinese provincial eco-compensation in the future (TFEMP, CCICED, 2007; Gong, 2011; Liu G et al., 2013). For example, in upstream areas of the Zhanghe River, Shanxi, Hebei, and Henan had conducted trans-provincial water rights transfer compensation. Another example is located in the Dongjiang riverhead area, where Jiangxi and Guangdong have also conducted water rights transfer compensation. Beijing and Hebei have also conducted trans-provincial eco-compensation projects (Gong, 2011; Liu G et al., 2013; Huang, 2012).

In recent years, China has made huge achievements in provincial eco-compensation, both in theory and in practice (Task Force on Eco-compensation Mechanisms and Policies, CCICED, 2007; Gong, 2011; Liu G et al., 2013). However, at the same time, differences in provincial eco-compensation frameworks have become apparent (Gong, 2011; Liu G et al., 2013; Kong, 2010; Li et al., 2010; Ding et al., 2010). Differences in eco-compensation frameworks are apparent not only at the national level, but also at the provincial or inter-regional levels, and these differences have become important issues for researchers and the public. When we study the issue of differences in Chinese provincial eco-compensation framework, we must first establish how to measure such differences and their changes. There have been few systematic studies that have measured provincial differences in eco-compensation, with most undertaking theoretical research of the theoretical framework, and compensation standards, mechanisms and types, using case studies. Studies of provincial differences in eco-compensation at the macro-scale are limited.

In this study, we investigated the theoretical framework and used various measurement methods to determine provincial differences in eco-compensation in China. We also analyzed the spatial differences in provincial eco-compensation, and considered differences in provincial eco-compensation over long time periods, including the differences in the detail and driving mechanisms of provincial eco-compensation. The conclusions can be used to improve theoretical studies of eco-compensation. At the same time, from a practical perspective, because of regional differences in China, one type of compensation may be unreasonable for application in other regions or by different bodies. The conclusions can be used to enable government to formulate a regionally related eco-compensation policy, enabling 
different zones to understand their own status in the national eco-compensation framework, and for establishing a national control on eco-compensation schemes.

\section{Principles and methods}

\subsection{Theoretical framework}

In China and overseas, studies have been undertaken to measure the quantity of eco-compensation. In this study, from the geographical perspective of scale relevance and scale transition, and with reference to existing methods of measuring regional differences, we propose a theoretical framework and measurement method to investigate provincial differences in eco-compensation.

\subsubsection{Mechanism used to analyze provincial eco-compensation}

In consideration of existing eco-compensation research (Pagiola et al., 2005, 2007), and from a geographical perspective of scale relevance and scale transition, we described the logical framework of provincial eco-compensation in China (Figure 1a). When a region's "quantity of pollutants discharged (converted to the corresponding cost of pollution abatement)" is subtracted from the "eco-resources value", and then added to the "economic input of pollution abatement", a positive value [i.e., eco-resources value - quantity of pollutant discharged (converted to the corresponding cost of pollution abatement) + the economic input of pollution abatement) $>0$ ] means the region makes a positive contribution to the ecological construction of the whole nation (Liu et al., 2014; Zhang et al., 2015).

\subsubsection{Mechanism used to analyze differences in provincial eco-compensation}

In general, there are large differences in eco-compensation standards and the spatial and temporal distribution of eco-compensation between different regions. This is due to differences in the value of regional ecological resources, regional pollution control inputs, and regional pollution emissions, in combination with differences in national regulations and regional self-development (Figure 1b). Studies of these regional differences have been a key focus of geographers. Attempts have been made to determine the actual differences, how large they are, what factors cause them, and what the trends are in the development of regional differences (Liu $\mathrm{W}$ et al., 2013b). To measure provincial differences in eco-compensation, we used related research findings regarding regional differences as a reference (Liu W et al., 2013; Long, 1999; Kim et al., 2001; Guang, 2001; Jonathan et al., 2002; Liu, 2006; Liu W et al., 2013b). We focused on the key issues of the formation mechanisms of provincial differences in eco-compensation, regional differences at different spatial scales, changes in regional differences over a time series, and an analysis and comparison of the detailed differences (Figure 1c).

\subsection{Calculation methods}

\subsubsection{Calculation of a provincial eco-compensation standard}

The calculation of an eco-compensation standard is the basis of a provincial eco-compensation standard scheme. According to the mechanism of analysis of provincial eco-compensation presented in Figure 1, to calculate a provincial eco-compensation standard, we used the following frameworks: (1) measure an ecological value equivalent, (2) account for 
(a)

Provincial eco-compen sation mechanism

(b)

Analysis of differences

in ecocompensation

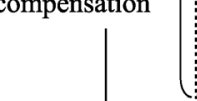

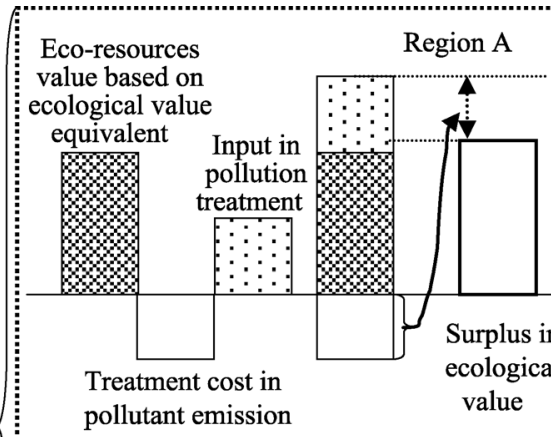

Region B

Eco-resources value based on ecological value Input in equivalent pollution $\%$ treatment

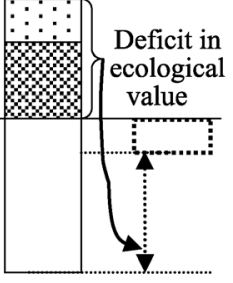

Treatment cost in pollutant emission
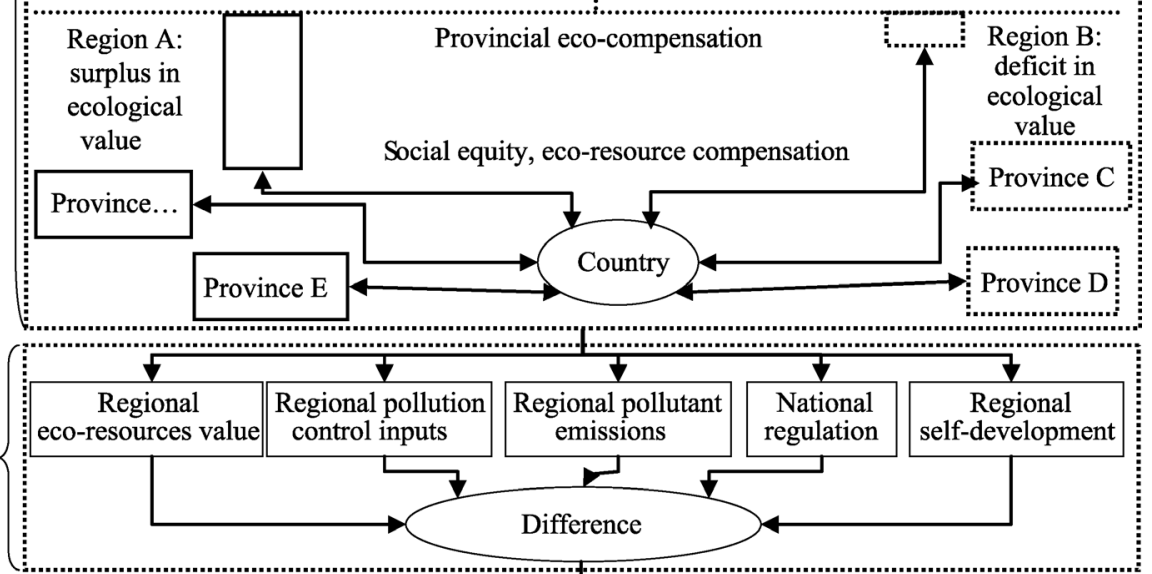

(c)

Measurement of differences

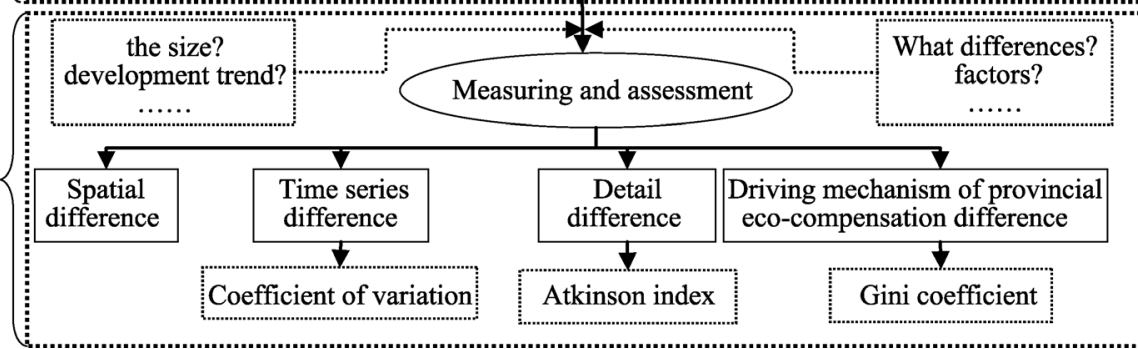

Figure 1 Logical framework of provincial eco-compensation and an analysis of its differences

ecological value based on the ecological value equivalent, and (3) calculate the ecological economic surplus value (provincial eco-compensation standard) (Liu et al., 2014).

(1) Measuring an ecological value equivalent

Based on the concept of normalization, we considered the ecological value of a forest ecosystem as a reference, and consulted related published research (Xie et al., 2008), to obtain an ecological value equivalent scale for different ecosystems. The ecological value equivalent of forest was set to 1 , and then grassland was 0.42 , farmland was 0.28 , wetland was 1.95 , rivers and lakes were 1.61 , and desert was 0.05 .

(2) Accounting for ecological value based on the ecological value equivalent

The provincial ecological value equivalent was calculated using Eq.1:

$$
Q=S_{\mathrm{F}} \times F_{\mathrm{E}}+S_{\mathrm{G}} \times G_{\mathrm{E}}+S_{\mathrm{C}} \times C_{\mathrm{E}}+S_{\mathrm{W}} \times W_{\mathrm{E}}+S_{\mathrm{D}} \times D_{\mathrm{E}}+S_{\mathrm{R}} \times R_{\mathrm{E}}
$$

where $Q$ is the total ecological value equivalent, $S$ is ecosystem area, $E$ is the ecological 
value equivalent of the ecosystem, $F$ is the ecological value equivalent of forest, $G$ is the ecological value equivalent of grassland, $C$ is the ecological value equivalent of farmland, $W$ is the ecological value equivalent of wetland, $D$ is the ecological value equivalent of desert, and $R$ is the ecological value equivalent of rivers and lakes. For example, $S_{\mathrm{F}}$ represents forest ecosystem area and $F_{\mathrm{E}}$ represents the ecological value equivalent of a forest ecosystem.

Provincial ecological value was calculated using Eq.2:

$$
H=Q \times U \times \lambda
$$

where $H$ is the economic value (yuan) of ecological resource of a region, $Q$ is the total ecological value equivalent, $U$ is the economic value of a unit of ecological value equivalent, and $\lambda$ is a coefficient (the coefficient is a positive number, which is a scenario adjustment and amends the economic value of a unit ecological value equivalent; in this study, $\lambda=1$ ). According to Xie Gaodi et al. (2008), in 2007 in China, the economic value of a unit ecological value equivalent was 449.1 yuan/ha. Based on changes in the Chinese agricultural production price index, we calculated the economic value of a unit ecological value equivalent over the subsequent years in China. We assumed that there was little difference in the average price of agricultural production among provinces, which, due to the large amount of subsidy in agricultural production and agricultural machinery in China, was considered reasonable. For each province it was possible to obtain the mean economic value of a unit ecological value equivalent, and then obtain an overall mean value. For example, in 2011, the mean economic value of the unit ecological value equivalent for each province in China was 603.3 yuan $/ \mathrm{hm}^{2}$.

(3) Calculating the ecological economic surplus value (provincial eco-compensation standard)

The ecological economic surplus value was calculated using Eq. 3:

$$
Y=H+I-\sum\left(T_{\mathrm{K}} \times V_{\mathrm{K}}\right)
$$

where $H$ is the economic value of regional ecological resources, $I$ is the input in pollution treatment, $T$ is the total amount of pollution discharged, $V$ is the economic input for treating a unit of pollution discharged, and $K=1,2,3$ is the treatment of waste water, flue gas, and solid waste, respectively

\subsubsection{Different methods for analyzing provincial eco-compensation}

By referring to the existing methods of measuring regional differences (Liu, 2006; Liu W et al., 2013; Zhang et al., 2011; Chen, 2009; Athar et al., 1994), we applied the three metrics of the coefficient of variation, Atkinson index, and Gini coefficient to analyze the time series, details, and driving mechanisms of provincial differences in eco-compensation in China.

(1) Analysis of a time series of provincial differences in eco-compensation

To analyze a time series of provincial differences in eco-compensation, we used the coefficient of variation to compare the differences between years. In view of the population size, we used a weighting function to calculate each year's coefficient of variation. The computation was made using Eq. 4 (Liu, 2006):

$$
C V=\sqrt{\sum_{i=1}^{n}\left(y_{i}-E C_{u}\right)^{2} / q_{i} / E C_{u}}
$$

where $y_{i}(i=1,2,3, \ldots, n)$ is the per capita eco-compensation standard, $E C_{u}$ is the average per capita eco-compensation standard throughout the country, $n$ is the number of regions, 
and $q_{i}$ is the proportional population of area $i$ to the country as a whole.

(2) Analysis of the details of provincial differences in eco-compensation

The Atkinson index can identify the external visibility of regional differences in ecocompensation by establishing different parameters. If the regional differences within an area are small, and these changes cannot be observed by other methods, but we need to analyze them, we can use the Atkinson index method (Liu, 2006). To analyze and compare the details of provincial differences in eco-compensation, we used the Atkinson index method as given in Eq. 5 (Liu, 2006; Yuen, 1991):

$$
\mathrm{I}=1-\left[\sum_{i}\left(y_{i} / E C_{u}\right)^{1-\varepsilon} q_{i}\right]^{1 /(1-\varepsilon)}
$$

where $y_{i}(i=1,2,3, \cdots, n)$ is the per capita eco-compensation standard, $E C_{u}$ is the average per capita eco-compensation standard throughout the country, $q_{i}$ is the proportional population of area $i$ to the country as a whole, and $\varepsilon$ is a parameter related to imbalances in the external visibility of regional eco-compensation. If $\varepsilon=2$, the imbalance in external visibility is moderate (Liu, 2006; Yuen, 1991). In this study, $\varepsilon=2$.

(3) Analysis of the driving mechanism of provincial differences in eco-compensation

For the driving mechanism of provincial differences in eco-compensation we determined the factors influencing the extent of the differences. The Gini coefficient can be used to measure this. It was calculated using Eq. 6:

$$
G=\left[\sum_{i=1}^{n} \sum_{j=1}^{n}\left|y_{j}-y_{i}\right| q_{i} q_{j}\right] / 2 E C_{u}
$$

where $y_{i}$ (or $\left.y_{j}\right)(i, j=1,2,3, \ldots, n)$ is the per capita eco-compensation standard in area $i$ (or area $j), E C_{u}$ is the average value of the total compensation standard, $n$ is the number of regions, and $q_{i}$ (or $q_{j}$ ) is the proportional population of area $i$ (or area $j$ ) to the country as a whole.

The biggest advantage of using the Gini coefficient is that it can resolve the total difference into factorial differences, and then analyze the influence of the different factors on the total difference:

$$
G=\left(E C_{u 1} / E C_{u}\right) G^{*}{ }_{1}+\ldots+\left(E C_{u k} / E C_{u}\right) G^{*}{ }_{k}
$$

where $E C_{u}$ is the average value of the total compensation standard, $E C_{u k}$ is the average value of factor $k$, and $G^{*}{ }_{k}$ is the virtual Gini coefficient of factor $k$.

The virtual Gini coefficient is not the general Gini coefficient, but is calculated from Eq. 8. The virtual Gini coefficient can be a positive or negative number (Chen, 2009):

$$
G^{*}{ }_{k}=\left[\operatorname{cov}\left(y_{k}, F(y)\right)\right] /\left[\operatorname{cov}\left(y_{k}, F\left(y_{k}\right)\right)\right] \times\left[2 \operatorname{cov}\left(y_{k}, F\left(y_{k}\right)\right) / E C_{u}\right]
$$

To calculate the virtual Gini coefficient (Jonathan et al., 2002), we first ranked each province's eco-compensation standard and the data for each factor, $y_{1} \leqslant y_{2} \leqslant \ldots \leqslant y_{n}$. In Eq. 8, $\operatorname{cov}\left(y_{k}, F(y)\right)$ is the index of correlation of factor $k$ with the total eco-compensation's rank data, $\operatorname{cov}\left(y_{k}, \mathrm{~F}\left(y_{k}\right)\right)$ is the index of correlation of factor $k$ with factor $k$ 's rank data, and $E C_{u}$ is the average value of the total compensation standard.

$S_{k}$, the contribution of factor $k$ to the total difference, was calculated using Eq. 9:

$$
S_{k}=\left(E C_{u k} / E C_{u}\right) \times\left(G^{*}{ }_{k} / G\right)
$$

The contribution of factor $k$ to the total difference in eco-compensation not only depends on 
the value of factor $k$, but also depends on the value of the factor $k$ Gini coefficient as a proportion of the total Gini coefficient (Liu, 2006).

\section{An empirical study of the provincial differences in eco-compensation in China}

\subsection{Data sources}

For each province, we obtained the area of forest, grassland, farmland, wetland, rivers and lakes, and deserts, and related socio-economic data information. The main data sources we consulted were the China Statistical Yearbook (2005-2015) and China Environment Statistical Yearbook (2005-2015).

\subsection{Calculation of the provincial eco-compensation standard}

From 2004 to 2014, the overall condition of China's provincial eco-compensation standard did not change (Figure 2). The eco-compensation standards of developed provinces, such as Beijing, Shanghai, Guangdong, Tianjin, and Jiangsu, were negative, which means the development of these provinces had consumed the eco-resources of other regions. Therefore, the developed provinces should pay eco-compensation. The eco-compensation standards of developing provinces, such as Tibet, Qinghai, Xinjiang, Ningxia, Gansu, Yunnan, Guangxi, Inner Mongolia, and Heilongjiang, were positive, which means they should receive eco-compensation. In general, Inner Mongolia, Tibet, and Xinjiang were always the type of provinces that should receive eco-compensation, while Shanghai, Beijing, and other developed provinces were always the type of provinces that should pay eco-compensation.

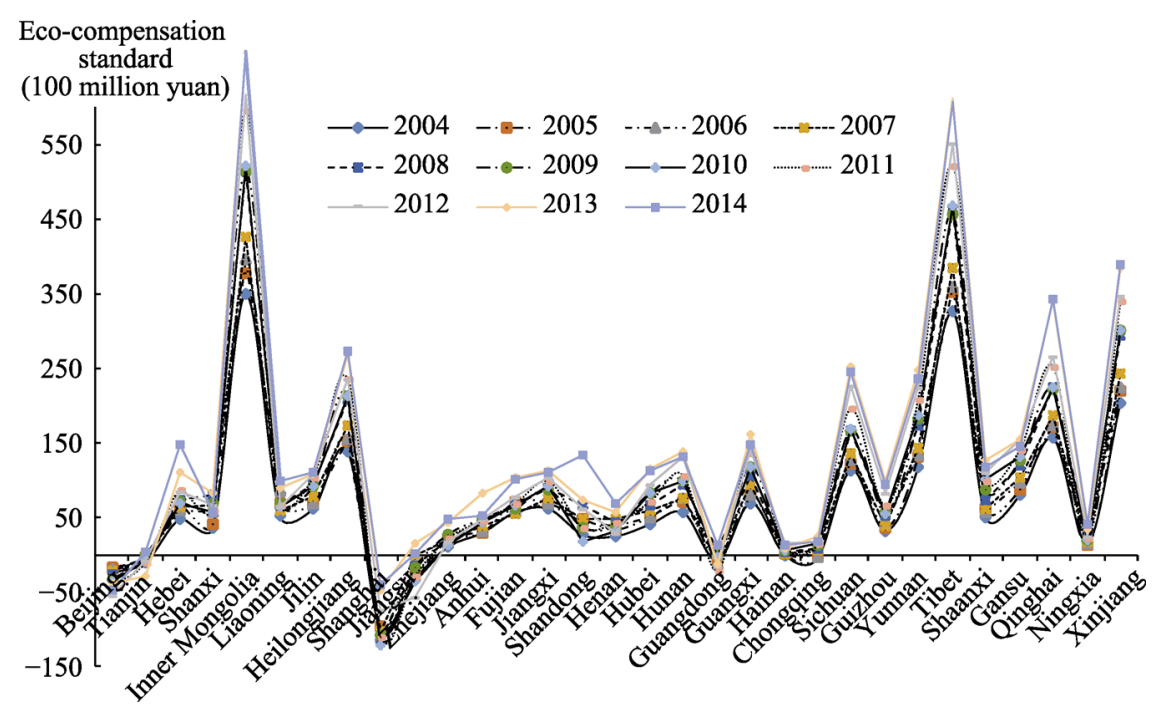

Figure 2 The value of the eco-compensation standard of each province in China from 2004 to 2014 Note: This study did not calculate the eco-compensation standard of Hong Kong, Macao, and Taiwan

To verify the authenticity of the calculated provincial eco-compensation standard we calculated the eco-compensation standard as a proportion of GDP to obtain a per capita eco-compensation standard (Tables 1 and 2). 
The results indicated that the eco-compensation standard as a proportion of GDP and the per capita eco-compensation standard were realistic values. Tibet had the largest eco-compensation standard as a proportion of GDP, followed by Qinghai, Xinjiang, Inner Mongolia, Gansu, Yunnan, Heilongjiang, Guangxi, Guizhou, and Ningxia. The eco-compensation standard as a proportion of GDP was the smallest for Guangdong, followed by Jiangsu, Zhejiang, Shandong, Tianjin, Chongqing, Henan, Anhui, Beijing and Liaoning. From the perspective of a per capita eco-compensation standard, of the provinces that should receive compensation, Tibet had the largest eco-compensation standard and Shandong had the smallest. Of the provinces that should pay eco-compensation, Shanghai had the largest standard, followed by Beijing, Tianjin, Jiangsu, and Guangdong. These results are comparable with those of other studies (Song et al., 2010; Jin, 2009).

Table 1 The eco-compensation standard as a proportion (\%) of GDP for each province in China from 2004 to 2014

\begin{tabular}{|c|c|c|c|c|c|c|c|c|c|c|c|}
\hline Province & 2004 & 2005 & 2006 & 2007 & 2008 & 2009 & 2010 & 2011 & 2012 & 2013 & 2014 \\
\hline Beijing & 0.39 & 0.24 & 0.23 & 0.23 & 0.23 & 0.27 & 0.25 & 0.25 & 0.31 & 0.19 & 0.22 \\
\hline Tianjin & 0.31 & 0.06 & 0.12 & 0.10 & 0.08 & 0.02 & 0.09 & 0.08 & 0.07 & 0.20 & 0.02 \\
\hline Hebei & 0.57 & 0.64 & 0.51 & 0.48 & 0.46 & 0.41 & 0.33 & 0.36 & 0.32 & 0.39 & 0.50 \\
\hline Shanxi & 0.99 & 0.96 & 1.17 & 1.12 & 1.11 & 0.94 & 0.61 & 0.54 & 0.55 & 0.65 & 0.45 \\
\hline Inner Mongolia & 11.49 & 9.64 & 8.03 & 6.62 & 6.04 & 5.28 & 4.46 & 4.15 & 3.88 & 4.00 & 3.80 \\
\hline Liaoning & 0.78 & 0.86 & 0.92 & 0.54 & 0.49 & 0.45 & 0.35 & 0.30 & 0.26 & 0.33 & 0.35 \\
\hline Jilin & 2.02 & 1.90 & 1.61 & 1.48 & 1.47 & 1.27 & 1.06 & 0.97 & 0.91 & 0.83 & 0.81 \\
\hline Heilongjiang & 2.91 & 2.74 & 2.49 & 2.44 & 2.52 & 2.49 & 2.04 & 1.87 & 1.72 & 1.87 & 1.82 \\
\hline Shanghai & 1.34 & 1.02 & 1.04 & 0.83 & 0.81 & 0.71 & 0.71 & 0.57 & 0.37 & 0.21 & 0.17 \\
\hline Jiangsu & 0.21 & 0.10 & 0.13 & 0.00 & 0.04 & 0.05 & 0.09 & 0.06 & 0.10 & 0.03 & 0.00 \\
\hline Zhejiang & 0.09 & 0.15 & 0.14 & 0.11 & 0.09 & 0.12 & 0.05 & 0.07 & 0.05 & 0.11 & 0.12 \\
\hline Anhui & 0.60 & 0.56 & 0.50 & 0.53 & 0.53 & 0.47 & 0.34 & 0.30 & 0.28 & 0.43 & 0.26 \\
\hline Fujian & 0.94 & 1.10 & 0.76 & 0.59 & 0.61 & 0.51 & 0.45 & 0.39 & 0.40 & 0.48 & 0.43 \\
\hline Jiangxi & 1.79 & 1.72 & 1.44 & 1.31 & 1.27 & 1.15 & 0.96 & 0.84 & 0.81 & 0.79 & 0.70 \\
\hline Shandong & 0.17 & 0.26 & 0.20 & 0.19 & 0.21 & 0.11 & 0.05 & 0.08 & 0.12 & 0.14 & 0.22 \\
\hline Henan & 0.30 & 0.33 & 0.30 & 0.32 & 0.25 & 0.20 & 0.14 & 0.17 & 0.10 & 0.18 & 0.20 \\
\hline Hubei & 0.72 & 0.77 & 0.67 & 0.63 & 0.59 & 0.64 & 0.52 & 0.36 & 0.43 & 0.47 & 0.41 \\
\hline Hunan & 1.01 & 1.07 & 0.99 & 0.82 & 0.83 & 0.75 & 0.62 & 0.54 & 0.60 & 0.56 & 0.49 \\
\hline Guangdong & 0.04 & 0.02 & 0.04 & 0.00 & 0.02 & 0.00 & 0.01 & 0.04 & 0.02 & 0.02 & 0.02 \\
\hline Guangxi & 2.03 & 1.99 & 1.68 & 1.61 & 1.53 & 1.53 & 1.24 & 1.16 & 1.07 & 1.13 & 0.95 \\
\hline Hainan & 0.05 & 0.14 & 0.31 & 0.19 & 0.30 & 0.34 & 0.28 & 0.40 & 0.51 & 0.30 & 0.38 \\
\hline Chongqing & 0.13 & 0.06 & 0.07 & 0.15 & 0.14 & 0.19 & 0.20 & 0.15 & 0.15 & 0.20 & 0.13 \\
\hline Sichuan & 1.78 & 1.64 & 1.45 & 1.29 & 1.31 & 1.18 & 0.98 & 0.93 & 0.95 & 0.96 & 0.86 \\
\hline Guizhou & 1.87 & 1.84 & 1.76 & 1.34 & 1.49 & 1.47 & 1.20 & 1.16 & 1.20 & 1.24 & 1.03 \\
\hline Yunnan & 3.83 & 3.77 & 3.37 & 3.01 & 3.06 & 2.96 & 2.61 & 2.33 & 2.18 & 2.11 & 1.84 \\
\hline Tibet & 147.62 & 140.27 & 122.96 & 112.86 & 117.39 & 103.26 & 92.37 & 86.18 & 78.54 & 75.70 & 65.81 \\
\hline Shaanxi & 1.74 & 1.67 & 1.25 & 1.06 & 1.02 & 1.08 & 1.01 & 0.80 & 0.76 & 0.80 & 0.67 \\
\hline Gansu & 4.77 & 4.56 & 4.23 & 3.87 & 3.79 & 3.75 & 3.21 & 2.81 & 2.74 & 2.46 & 2.13 \\
\hline Qinghai & 33.65 & 31.28 & 26.66 & 23.34 & 22.01 & 20.45 & 16.68 & 15.10 & 14.02 & 16.20 & 14.89 \\
\hline Ningxia & 3.09 & 2.09 & 2.17 & 1.83 & 2.03 & 1.47 & 1.18 & 1.05 & 1.08 & 1.32 & 1.46 \\
\hline Xinjiang & 9.02 & 8.36 & 7.35 & 6.90 & 7.02 & 7.05 & 5.54 & 5.13 & 4.62 & 4.60 & 4.19 \\
\hline
\end{tabular}


Table 2 The per capita eco-compensation standard for each province in China from 2004 to 2014 (yuan)

\begin{tabular}{|c|c|c|c|c|c|c|c|c|c|c|c|}
\hline Province & 2004 & 2005 & 2006 & 2007 & 2008 & 2009 & 2010 & 2011 & 2012 & 2013 & 2014 \\
\hline Beijing & -158.20 & -110.27 & -117.86 & -133.00 & -142.24 & -179.19 & -182.87 & -199.46 & -265.78 & -179.53 & -213.76 \\
\hline Tianjin & -93.07 & -19.94 & -50.70 & -45.56 & -47.79 & -10.42 & -61.20 & -65.39 & -60.74 & -191.86 & 20.69 \\
\hline Hebei & 71.39 & 94.67 & 85.45 & 93.49 & 105.75 & 100.10 & 94.80 & 121.93 & 116.62 & 152.27 & 200.63 \\
\hline Shanxi & 106.27 & 120.75 & 168.53 & 199.68 & 238.70 & 200.79 & 157.44 & 168.19 & 185.00 & 227.01 & 157.11 \\
\hline $\begin{array}{l}\text { Inner } \\
\text { Mongolia }\end{array}$ & 1459.67 & 1566.38 & 1643.48 & 1750.93 & 2100.86 & 2090.76 & 2108.05 & 2402.22 & 2472.26 & 2695.39 & 2692.56 \\
\hline Liaoning & 123.78 & 163.52 & 199.84 & 139.16 & 155.85 & 157.29 & 146.58 & 152.45 & 148.16 & 202.41 & 225.64 \\
\hline Jilin & 232.41 & 253.17 & 252.59 & 286.41 & 344.77 & 336.46 & 335.78 & 374.57 & 393.13 & 391.56 & 405.06 \\
\hline Heilongjiang & 361.75 & 396.07 & 405.47 & 453.92 & 546.90 & 557.97 & 552.70 & 614.50 & 614.48 & 702.84 & 712.29 \\
\hline Shanghai & -543.32 & -500.63 & -560.69 & -502.81 & -529.61 & -484.25 & -526.53 & -462.42 & -313.08 & -191.09 & -167.17 \\
\hline Jiangsu & -42.71 & -24.88 & -37.66 & -1.49 & -17.29 & -22.93 & -46.16 & -36.32 & -70.40 & 19.48 & 1.13 \\
\hline Zhejiang & 20.89 & 39.05 & 44.85 & 39.50 & 37.26 & 52.58 & 26.47 & 39.78 & 32.44 & 77.65 & 85.50 \\
\hline Anhui & 46.53 & 49.28 & 50.47 & 63.26 & 76.97 & 77.30 & 71.51 & 77.75 & 80.62 & 136.45 & 87.95 \\
\hline Fujian & 161.07 & 202.61 & 160.64 & 151.25 & 182.14 & 171.63 & 180.07 & 183.98 & 209.71 & 274.42 & 269.20 \\
\hline Jiangxi & 146.20 & 161.96 & 160.08 & 173.37 & 201.59 & 198.78 & 204.03 & 219.92 & 232.88 & 251.61 & 242.95 \\
\hline Shandong & 29.35 & 53.04 & 47.70 & 51.02 & 70.05 & 38.93 & 19.24 & 38.55 & 64.30 & 76.00 & 135.63 \\
\hline Henan & 26.04 & 37.00 & 40.24 & 50.64 & 47.10 & 40.52 & 34.56 & 47.46 & 31.74 & 53.51 & 64.48 \\
\hline Hubei & 71.15 & 88.53 & 90.04 & 102.86 & 116.56 & 145.28 & 144.45 & 122.46 & 164.38 & 199.16 & 194.08 \\
\hline Hunan & 85.37 & 111.08 & 119.77 & 121.13 & 149.50 & 153.22 & 150.96 & 160.51 & 199.77 & 205.66 & 196.89 \\
\hline Guangdong & -8.10 & -4.51 & -12.14 & -0.37 & 5.61 & -0.41 & -2.80 & -20.63 & -13.25 & -12.49 & 12.45 \\
\hline Guangxi & 142.65 & 173.71 & 171.60 & 197.02 & 222.36 & 244.38 & 257.07 & 292.03 & 299.19 & 306.83 & 312.17 \\
\hline Hainan & 4.40 & 15.70 & 39.00 & 28.52 & 52.81 & 64.70 & 65.36 & 115.85 & 165.13 & 106.52 & 147.27 \\
\hline Chongqing & -13.00 & -6.86 & -9.79 & 25.64 & 28.39 & 44.28 & 54.97 & 52.00 & 58.74 & 84.54 & 56.47 \\
\hline Sichuan & 140.62 & 147.86 & 154.25 & 168.01 & 203.59 & 204.13 & 209.72 & 243.49 & 279.53 & 310.87 & 302.16 \\
\hline Guizhou & 80.48 & 98.87 & 111.25 & 106.17 & 147.61 & 162.68 & 159.36 & 190.98 & 235.80 & 283.05 & 272.47 \\
\hline Yunnan & 267.59 & 293.87 & 300.98 & 318.54 & 382.85 & 400.13 & 409.28 & 447.31 & 482.06 & 527.07 & 500.30 \\
\hline Tibet & 11784.78 & 12584.29 & 12555.441 & 13333.22 & 15873.63 & 15396.28 & 15624.33 & 17231.681 & 17877.36 & 19594.461 & 19055.43 \\
\hline Shaanxi & 136.10 & 166.42 & 152.85 & 165.26 & 199.70 & 236.71 & 272.64 & 267.81 & 292.16 & 340.13 & 313.91 \\
\hline Gansu & 316.77 & 346.88 & 378.29 & 409.97 & 470.56 & 497.10 & 516.09 & 549.26 & 600.26 & 597.50 & 560.77 \\
\hline Qinghai & 2910.02 & 3129.65 & 3154.38 & 3371.92 & 4047.11 & 3968.94 & 4000.71 & 4441.20 & 4633.86 & 5890.33 & 5877.77 \\
\hline Ningxia & 281.97 & 214.93 & 261.26 & 275.41 & 394.66 & 317.60 & 315.17 & 346.48 & 389.62 & 515.76 & 608.41 \\
\hline Xinjiang & 1033.77 & 1097.51 & 1092.24 & 1159.62 & 1377.57 & 1397.13 & 1377.89 & 1535.90 & 1553.15 & 1699.85 & 1689.18 \\
\hline
\end{tabular}

\subsection{Analysis of provincial differences in eco-compensation in China}

\subsubsection{Spatial differences}

Seen from a geographic perspective (Figure 3), there is certain zonality in China's provincial eco-compensation. The "Hu Huanyong Line" can be taken as a boundary. Most of the provinces that are pierced by the "Hu Huanyong Line" or are located to its northwest side

\footnotetext{
1 The "Hu Huanyong Line" is indicated in Figure 3.
} 
(a) 2004

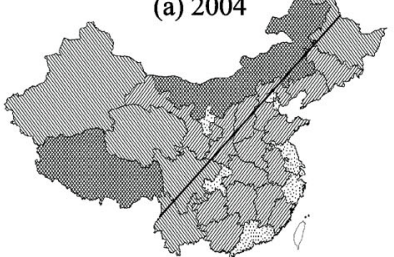

Eco-compensation quantity (100 million Yuan)

…:-99.700000

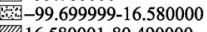

12] $16.580001-80.490000$

짜자. $202.930001-349.300000$

$0 \quad 1500 \mathrm{~km}$

(d) 2007

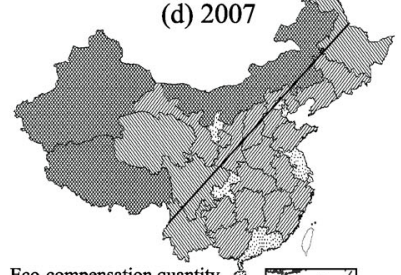

Eco-compensation quantity (100 million Yuan) …... -103.780000

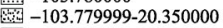

필 20.350001-104.460000

$104.460001-242.940000$

242.940001-425.300000

$0 \quad 1500 \mathrm{~km}$

(g) 2010

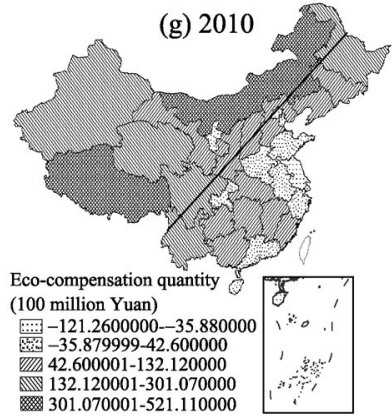

$0 \quad 1500 \mathrm{~km}$ (b) 2005

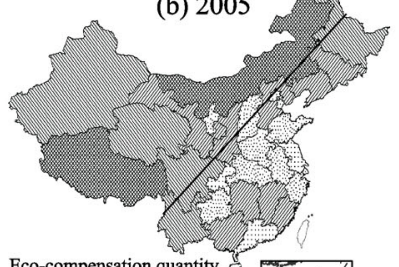

Eco-compensation quantity (100 million Yuan)

[...: -94.620000-1.300000

एगI $50.550001-88.280000$

$88.280001-220.600000$

$0 \quad 1500 \mathrm{~km}$

(e) 2008

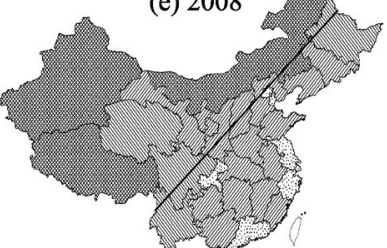

Eco-compensation quantity

(100 million Yuan)

(..... -113.390000

ㅊ:워 $-113.389999-24.390000$

24.390001-120.040000

120.040001-293.560000

$$
0 \quad 1500 \mathrm{~km}
$$

(h) 2011

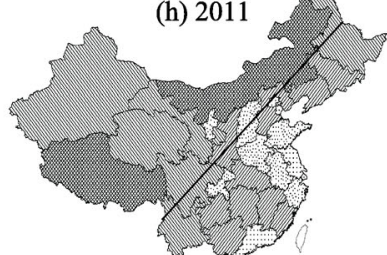

Eco-compensation quantity (100 million Yuan)

(100 million Yuan) :.:. $-108.530000-8.860000$ $60.430001-140.830000$

140.830001-339.280000 339.280001-596.230000

$0 \quad 1500 \mathrm{~km}$ (c) 2006

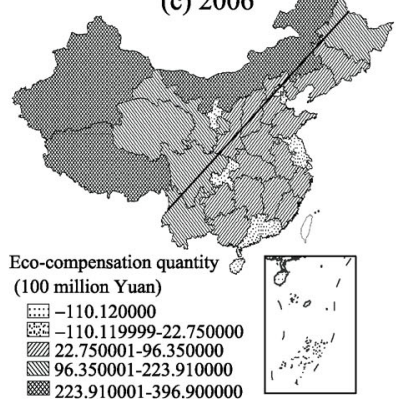

$0 \quad 1500 \mathrm{~km}$

(f) 2009

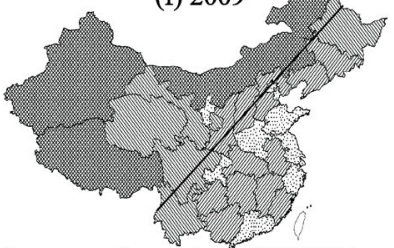

Eco-compensation quantity (100 million Yuan) :-:.:-107.020000 圈 $-107.019999-38.440000$ 38.440001-127.010000 127.010001-301.640000 $0 \quad 1500 \mathrm{~km}$

(i) 2012

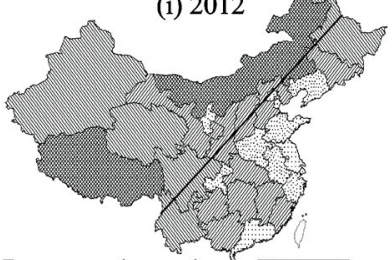

Eco-compensation quantity (100 million Yuan)

$-74.510000-8.58000$

$66.800001-154.750000$

154.750001-346.820000

346.820001-615.590000

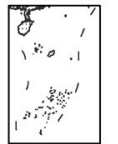

$0 \quad 1500 \mathrm{~km}$

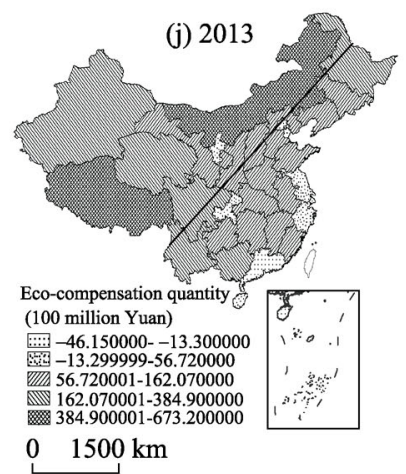

(k) 2014

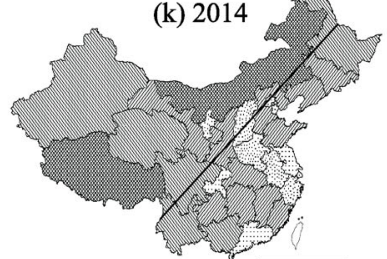

(100 million Yuan)

…. -46.000500-19.060000

19.060001-68.750000

68.750001-148.400000

148.400001-388.200000

$0 \quad 1500 \mathrm{~km}$

Figure 3 Spatial distribution of the provincial eco-compensation standard in China from 2004 to 2014 


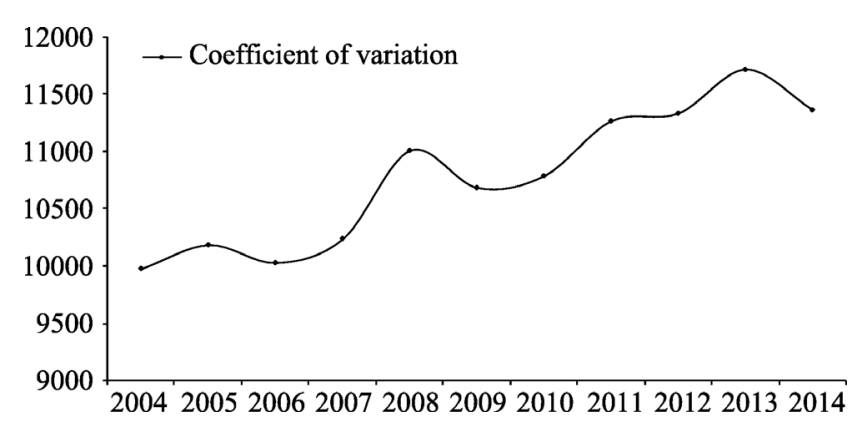

Figure 4 The coefficient of variation of provincial eco-compensation in China from 2004 to 2014

and has a small population. The main priorities in this area are ecological restoration and protection.

\subsubsection{Time series of provincial differences in eco-compensation}

The coefficient of variation is a suitable parameter for analyzing variations in a time series (Liu W et al., 2013b; Liu, 2006). By calculating the coefficient of variation for China's provincial eco-compensation from 2004 to 2014 (Figure 4), we found that in recent years the provincial differences in eco-compensation have tended to increase, with an annual average increase of 1.4\%. However, there were fluctuations in 2006, 2009, and 2014 when the differences were not as large. The largest annual average value of the coefficient of variation was $7.5 \%$ in 2008 , and the next largest values were $4.5 \%$ in $2011,3.4 \%$ in 2013 , and $2.1 \%$ in 2005 and 2007. In 2009 and 2014 the value was $-3 \%$, which was the largest reduction in the coefficient of variation, with the next largest being $-1.5 \%$ in 2006.

\subsubsection{Details of the provincial differences in eco-compensation}

The Atkinson index is a suitable metric for analyzing the details (i.e., rate of increase or decrease) of the provincial differences in eco-compensation. It can be seen from Figure 5 that in recent years, the provincial differences in eco-compensation in China have increased, with an annual average rate of increase of $23.9 \%$. In 2005, 2006, 2013, and 2014, the rate of increase was larger, at $284.8 \%, 105.3 \%, 254.4 \%$, and $71.5 \%$, respectively. In 2009 and 2010, the rate of increase was $7.7 \%$ and $5.7 \%$, respectively. However, in 2007 , 2008, 2011, and 2012 the rate of increase became negative at $-56.2 \%$, $-7.1 \%,-48 \%$, and $-70.7 \%$, respectively.

3.3.4 The driving mechanism of provincial differences in eco-compensation In 2004-2014, the Gini coefficient of provincial differences in eco-compen-

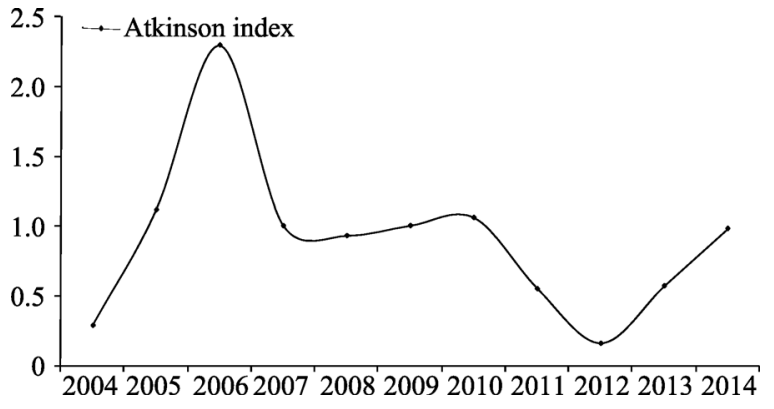

Figure 5 Atkinson index values of provincial differences in eco-compensation in China from 2004 to 2014

\footnotetext{
2 The eco-compensation standards of Gansu are increasing annually and are similar to those of Qinghai and Sichuan. The eco-compensation standard is small in Ningxia owing to its small area.
} 
sation showed a tendency of increasing fluctuation (Figure 6). In most years, especially from 2004 to 2012, there was a tendency for fluctuations to increase, but in recent years this tendency has declined.

By calculating the virtual Gini index, we can decompose the total provincial differences in eco-compensation into various factors that influence the difference. The contribution of the factors determined from the virtual Gini index of China's provincial eco-compensation in 2014 are shown in Table 3.

Table 3 Factors affecting the provincial differences in eco-compensation in China in 2014

\begin{tabular}{lccc}
\hline \multicolumn{1}{c}{ Factor of influence } & $\mathrm{G}^{*}$ (virtual) & G (total) & S (factor contribution) \\
\hline Eco-resources value & 0.018 & 0.029 & 0.733 \\
Economic input of pollution abatement & 0.017 & & 0.077 \\
Cost of pollution abatement & 0.018 & 0.190 \\
\hline
\end{tabular}

It can be seen from Table 3 that the value of eco-resources played the decisive role in provincial differences in eco-compensation in China, with a proportional contribution of $73.3 \%$. The next most important factor was the cost of pollution abatement, with a contribution of $19 \%$. The economic input of pollution abatement had a minor role, with a contribution of less than $8 \%$. Enhancing the value of provincial eco-resources and reducing pollution emissions are the main considerations when regulating provincial eco-compensation.

\section{Conclusions and discussion}

\subsection{Research conclusions}

(1) Inspired by the work of Pagiola and others with regard to eco-compensation, we described the logical framework of provincial eco-compensation in China, expounded the theoretical framework of measuring provincial differences in eco-compensation, and investigated the variation in a time series of these differences, the details of the differences, and the driving mechanism of provincial differences in eco-compensation in China.

(2) Using statistical data for the provinces of China from 2004 to 2014, we calculated a provincial eco-compensation standard, determined the eco-compensation standard as a proportion of GDP, and calculated a per capita eco-compensation standard. The results confirmed that the eco-compensation standard as a proportion of GDP and the per capita eco-compensation standard produced realistic values. Seen from a geographic perspective, most of the provinces that are pierced by the "Hu Huanyong Line" or are located to the northwest of the line should receive eco-compensation. 
(3) We calculated the coefficient of variation, Atkinson index, and Gini coefficient of China's provincial eco-compensation. From 2004 to 2014, provincial differences in eco-compensation in China had a tendency to increase, but there were fluctuations in this trend in some years. The range of the Atkinson index was larger than that of the other two indices. The Atkinson index is suitable for analyzing the detailed differences in provincial eco-compensation.

(4) Among the curves produced to represent the whole time series there were differences in the peaks and troughs produced by the different methods. In the short-term, the analysis results indicated a lack of conformity in the degree of difference produced by each index. Over the long-term, the tendency for variation was similar among the three indices. When considering provincial differences in eco-compensation, we should obtain the long-term tendency for variation as a reference. The results obtained in this study were comparable with those obtained from other studies.

(5) By calculating the virtual Gini index it was found that the value of eco-resources played a decisive role in provincial differences in eco-compensation in China, accounting for $73.3 \%$ of the overall differences. The next most important factor was the cost of pollution abatement, which accounted for $19 \%$ of the differences. The economic input on pollution abatement had a minor role, accounting for just $7.7 \%$ of the differences. By enhancing the protection and establishment of forest, grassland, farmland, wetland, and river and lake eco-resources, and reducing waste water, atmospheric emissions, waste residues and other forms of pollution, provincial eco-compensation will be effectively regulated.

\subsection{Limitations of this study}

Due to data limitations this study just applied the methods of the coefficient of variation, Atkinson index, and Gini coefficient, and investigated the variation in a time series of these differences, the details of the differences, and the driving mechanism of provincial differences in eco-compensation in China. In practice, there are other methods that could have been applied, such as the Selma index and index system methods. Whether these methods are suitable to measure provincial differences in eco-compensation requires further investigation.

\section{References}

An Xiaoming, Guo Zhiyuan, 2012. Research on the government actions in inter-provincial eco-compensation. Guangxi Social Sciences, (7): 109-114. (in Chinese)

Athar Hussain, Peter Lanjouw, Nicholas Stern, 1994. Income inequalities in China: Evidence from household survey data. World Development, 22(12): 1947-1957.

Börner J, Wunder S, Wertz-Kanounnikoff S et al., 2010. Direct conservation payments in the Brazilian Amazon: Scope and equity implications. Ecological Economics, 69(6): 1272-1282.

Boyd J, Banzhaf S, 2007. What are ecosystem services? The need for standardized environmental accounting units. Ecological Economics, 63(2): 616-626.

Cai B C, Wen L Q, Lu G F, 2005. Theories for mechanism of ecological compensation. Ecological Economy, (1): 47-50.

Chen Cai, 2009. Regional Economic Geography. 2nd ed. Beijing: Science Press, 6-86. (in Chinese)

Chen Chuanming, 2011. Ecological compensation mechanism in Wuyishan National Nature Reserve of Fujian 
Province, China. Scientia Geographica Sinica, 31(5): 594-599. (in Chinese)

Corbera E, Soberanis C G, Brown K, 2009. Institutional dimensions of payments for ecosystem services: An analysis of Mexico's carbon forestry programme. Ecological Economics, 68(3): 743-761.

Dai Qiwen, 2010. Study on the spatial selection of ecological compensation objects: A case study of water conservation of grasslands in Gannan Tibetan Autonomous Prefecture. Journal of Natural Resources, 25(3): 415-425. (in Chinese)

Ding Sibao, Wang Xiaoyun, 2008. Theory and mechanism of the regional eco-environmental compensation. Journal of Northeast Normal University (Philosophy and Social Sciences), (4): 5-10. (in Chinese)

Ding Sibao, Wang Yu, 2010. Study on the Basic Theory and Practical Problems of Regional Eco-compensation. Beijing: Science Press, 11-97. (in Chinese)

Ding Sibao, Wang Yu, Lu Yanli et al., 2012. Main Function Zoning and Regional Eco-compensation. Beijing: Science Press, 5-76. (in Chinese)

Gong Gaojian, 2011. Study on Some Problems of Eco-compensation in China. Beijing: China Social Sciences Publishing House, 6-78. (in Chinese)

Guang Hua Wan, 2001. Changes in regional inequality in rural China: Decomposing the Gini Index by income sources. The Australian Journal of Agricultural and Resource Economics, 45(3): 361-381.

Hawkes C V, Sullivan J J, 2001. The impact of herbivory on plants in different resource conditions: A meta-analysis. Ecology, 82(7): 2045-2058.

$\mathrm{Hu}$ Wenwei, Du Huanzheng, Li Bing, 2007. Setting up interregional ecological compensation mechanism to advance coordinated development of regional economy. Journal of Jiaxing University, 19(1): 5-7, 57. (in Chinese)

Huang Huan, 2012. On Interregional Eco-compensation. Beijing: China Renmin University Press, 3-69. (in Chinese)

Huang Lihong, Chen Ting, Lin Wenxiong, 2010. Subdividing the type of ecological compensation and designing plan during construction of economic zone on the west side of the strait. Chinese Agricultural Science Bulletin, 26(7): 252-256. (in Chinese)

Jiang Xiujuan, 2010. Research on types and methods of ecological compensation [D]. Qingdao: Ocean University of China. (in Chinese)

Jin Yan, 2009. The quantitative research of ecological compensation in multiple temporal and spatial scales [D]. Hangzhou: Zhejiang University. (in Chinese)

Johst K, Drechsler M, Wätzold F, 2002. An ecological-economic modelling procedure to design compensation payments for the efficient spatio-temporal allocation of species protection measures. Ecological Economics, 41(1): 37-49.

Jonathan Morduch, Terry Sicular, 2002. Rethinking inequality decomposition, with evidence from rural China. The Economic Journal, 112: 93-106.

Kim T J, Knaap G J, 2001. The spatial dispersion of economic activities and development trends in China: 1952-1985. The Annals of Regional Science, 35(1): 39-57.

Kong Fanbin, 2010. Eco-compensation Mechanism of China: Theory, Practice and Policy Design. Beijing: China Environmental Science Press, 7-98. (in Chinese)

Kosoy N, Corbera E, 2010. Payments for ecosystem services as commodity fetishism. Ecological Economics, 69(6): 1228-1236.

Li Hao, Huang Wei, Liu Tao et al., 2011. Ecological compensation mechanism on inter-basin water transfer. Journal of Natural Resources, 26(9): 1506-1512. (in Chinese)

Li Ning, Ding Sibao, 2009. Institutional construction of establishing and improving inter-regional eco-compensation mechanism in China. China Population Resources and Environment, 19(1): 146-149. (in Chinese)

Li Pingxing, Sun Wei, 2010. Theoretical reflection on ecological compensation from the perspective of economic geography. Ecology and Environmental Sciences, 19(6): 1507-1512. (in Chinese)

Li Qing, Zhang Luocheng, Wu Qinghua, 2011. Questionnaire survey on willingness to pay about ecological compensation of Lake Tianmu catchment, Taihu Basin. Journal of Lake Sciences, 23(1): 143-149. (in Chinese)

Li Wenhua, Li Shidong, Li Fen et al., 2007. Discussions on several issues of forest eco-compensation mechanism. 


\section{China Population Resources and Environment, 17(2): 13-18. (in Chinese)}

Liu Chunla, Liu Weidong, Lu Dadao, 2015. China's provincial eco-compensation difference in 2004-2011. Acta Geographica Sinica, 70(12): 1897-1910. (in Chinese)

Liu Chunla, Liu Weidong, Lu Dadao et al., 2016. Eco-compensation and harmonious regional development in China. Chinese Geographical Science, 26(3): 283-294.

Liu Chunla, Liu Weidong, Xu Mei, 2014. The provincial eco-compensation standard of China based on ecological value equivalents. Resources Science, 36(1): 148-155. (in Chinese)

Liu Guihuan, Lu Jun, Wang Xiahui, 2013. Overview of Ecological Compensation Policy in China. Beijing: China Environmental Science Press, 5-84. (in Chinese)

Liu Hui, 2006. Regional inequality measurement: Methods and evaluations. Geographical Research, 25(4): 710-718. (in Chinese)

Liu Weidong et al., 2013a. Report on Regional Development of China in 2011. Beijing: The Commercial Press, 4-95. (in Chinese)

Liu Weidong et al., 2013b. Economic Geography Thought. Beijing: Science Press, 10-124. (in Chinese)

Long Genying, 1999. China's changing regional disparities during the reform period. Economic Geography, 75(1): 59-70.

Ma Aihui, Cai Yinying, Zhang Anlu, 2012. An empirical study of cultivated land ecological compensation based on choice experiments method. Journal of Natural Resources, 27(7): 1154-1163. (in Chinese)

Pagiola S, Areenas A, Platais G, 2005. Can payments for environmental services help reduce poverty? An exploration of the issues and the evidence to date from Latin America. World Development, 33(2): 237-253.

Pagiola S, Platais G, 2007. Payments for environmental services: From theory to practice. Washington D C: World Bank.

Qin Yanhong, Kang Muyi, 2007. A review of ecological compensation and its improvement measures. Journal of Natural Resources, 22(4): 557-567. (in Chinese)

Ruan Benqing, Xu Fengran, Zhang Chunling, 2008. Review of research and practice of river basin ecological compensation. Journal of Hydraulic Engineering, 39(10): 1220-1225. (in Chinese)

Salzman J, Ruhl J B, 2000. Currencies and the commodification of environmental law. Stanford Law Review, 53(3): 607-694.

Song B, Zhang X X, Xin Y L et al., 2010. Ecological compensation accounting for provinces in China based on ecological footprint. International Conference on Engineering and Business Management (EBM 2010), 3621-3626.

Strauss S Y, Agrawal A A, 1999. The ecology and evolution of plant tolerance to herbivory. Trends in Ecology \& Evolution, 14(5): 179-185.

Sustainable Development Strategy Research Group in the Administrative Center for China's Agenda 21 (SDSRG, ACCA), 2007. Ecological compensation: International Experiences and Chinese Practice. Beijing: Social Sciences Academic Press, 2-58. (in Chinese)

Task Force on Eco-compensation Mechanisms and Policies (TFEMP), CCICED, 2007. Eco-compensation Mechanisms and Policies in China. Beijing: Science Press, 15-97. (in Chinese)

The Administrative Center for China's Agenda 21 (ACCA), 2012. International Comparison of Ecological Compensation: Pattern \& Mechanism. Beijing: Social Sciences Academic Press, 10-65. (in Chinese)

Wang Nüjie, Liu Jian, Wu Daqian et al., 2010. Regional eco-compensation based on ecosystem service assessment: A case study of Shandong Province. Acta Ecologica Sinica, 30(23): 6646-6653. (in Chinese)

Wang Yu, Ding Sibao, Lu Yanli, 2011. Research on the standard for regional ecological compensation in China. China Development, 11(6): 1-5. (in Chinese)

Wätzold F, Drechsler M, 2005. Spatially uniform versus spatially heterogeneous compensation payments for biodiversity-enhancing land-use measures. Environmental and Resource Economics, 31(1): 73-93.

Wu Minghong, Yan Geng, 2013. Research on the determination method for provincial eco-compensation standard in China. Theoretical Investigation, (2): 105-107. (in Chinese)

Wu Xiaoqing, Hong Shangqun, Duan Changqun et al., 2003. Inter-regional ecological compensation system and 
regional coordinative development. Resources and Environment in the Yangtze Basin, 12(1): 13-16. (in Chinese)

Wunder S, Engel S, Pagiola S, 2008. Taking stock: A comparative analysis of payments for environmental services programs in developed and developing countries. Ecological Economics, 65(4): 834-852.

Wünscher T, Engel S, Wunder S, 2008. Spatial targeting of payments for environmental services: A tool for boosting conservation benefits. Ecological Economics, 65(4): 822-833.

Xie Gaodi, Cao Shuyan, Lu Chunxia et al., 2015. Current status and future trends for eco-compensation in China. Journal of Resources and Ecology, 6(6): 355-362.

Xie Gaodi, Zhen Lin, Lu Chunxia et al., 2008. Expert knowledge based valuation method of ecosystem services in China. Journal of Natural Resources, 23(5): 911-919. (in Chinese)

Xiong Ying, Wang Kelin, Lan Wanglian et al., 2004. Evaluation of the lake recovery area eco-compensation in Dongting Lake wetland. Acta Geographica Sinica, 59(5): 772-780. (in Chinese)

$\mathrm{Xu}$ Dawei, Li Bin, 2015. Research on regional ecological compensation performance appraisal based on propensity score analysis. China Population, Resources and Environment, 25(3): 34-42. (in Chinese)

Yang Guangmei, Min Qingwen, Li Wenhua et al., 2007. Scientific issues of ecological compensation research in China. Acta Ecologica Sinica, 27(10): 4289-4300. (in Chinese)

Yang Xin, Cai Yinying, 2012. Farmers' election of farmland ecological compensation mode and its relevant factors: A case of 383 households in Wuhan city. Resources and Environment in the Yangtze Basin, 21(5): 591-596. (in Chinese)

Yuan Weiyan, Zhou Xiaoke, 2014. Review of research progress abroad in payments for ecosystem services. China Population, Resources and Environment, 24(11): 76-82. (in Chinese)

Yuen Tsui K, 1991. China's regional inequality, 1952-1985. Journal of Comparative Economics, 15(1): 1-21.

Zhang Dongmei, Shu Yanfei, 2011. Regional Economy Analysis Method. Beijing: China Social Sciences Publishing House, 15-77. (in Chinese)

Zhang Sixue, Lin Hanchuan, Fang Wei et al., 2015. Study on the system of assessing value of eco-compensation mechanisms. Resources Science, 37(10): 1912-1919. (in Chinese)

Zhang Wei, Zhang Hongye, Zhang Yifeng, 2010. The determination of social ecological compensation standard based on "equivalent value of geographical factor endowment". Acta Geographica Sinica, 65(10): 1253-1265. (in Chinese)

Zhao Cuiwei, Wang Shijie, 2010. Benefits and standards of ecological compensation: International experiences and revelations for China. Geographical Research, 29(4): 597-606. (in Chinese) 